\title{
Bacterial communities associated with the midgut microbiota of wild Anopheles gambiae complex in Burkina Faso
}

\author{
Abdou Azaque Zoure ${ }^{1,2}$ (D) Abdoul Razack Sare ${ }^{3} \cdot$ Félix Yameogo $^{4} \cdot$ Zéphirin Somda $^{4} \cdot$ Sébastien Massart ${ }^{3}$. \\ Athanase Badolo ${ }^{4} \cdot$ Frédéric Francis ${ }^{1}$
}

Received: 9 April 2019 / Accepted: 9 October 2019

(c) Springer Nature B.V. 2019

\begin{abstract}
Plasmodium falciparum is transmitted by mosquitoes from the Anopheles gambiae sensu lato (s.l) species complex and is responsible for severe forms of malaria. The composition of the mosquitoes' microbiota plays a role in P. falciparum transmission, so we studied midgut bacterial communities of An. gambiae s.l from Burkina Faso. DNA was extracted from 17 pools of midgut of mosquitoes from the Anopheles gambiae complex from six localities in three climatic areas, including cotton-growing and cotton-free localities to include potential differences in insecticide selection pressure. The v3-v4 region of the 16S rRNA gene was targeted and sequenced using Illumina Miseq $(2 \times 250 \mathrm{nt})$. Diversity analysis was performed using QIIME and R software programs. The major bacterial phylum was Proteobacteria (97.2\%) in all samples. The most abundant genera were Enterobacter (32.8\%) and Aeromonas (29.8\%), followed by Pseudomonas (11.8\%), Acinetobacter $(5.9 \%)$ and Thorsellia (2.2\%). No statistical difference in operational taxonomic units (OTUs) was found (Kruskal-Wallis FDR $-p>0.05$ ) among the different areas, fields or localities. Richness and diversity indexes (observed OTUs, Chao1, Simpson and Shannon indexes) showed significant differences in the cotton-growing fields and in the agroclimatic zones, mainly in the Sudano-Sahelian area. OTUs from seven bacterial species that mediate refractoriness to Plasmodium infection in An. gambiae s.l were detected. The beta diversity analysis did not show any significant difference. Therefore, a same control strategy of using bacterial species refractoriness to Plasmodium to target mosquito midgut bacterial community and affect their fitness in malaria transmission may be valuable tool for future malaria control efforts in Burkina Faso.
\end{abstract}

Keywords Midgut bacteria $\cdot$ Anopheles gambiae $\mathrm{s} .1$ complex $\cdot$ Microbiota $\cdot$ Malaria

Electronic supplementary material The online version of this article (https://doi.org/10.1007/s11033-019-05121-x) contains supplementary material, which is available to authorized users.

Abdou Azaque Zoure

abdouazaque@gmail.com; entomologie.gembloux@ulg.ac.be

1 Functional and Evolutionary Entomology, TERRA, Gembloux Agro-Bio Tech, University of Liège, Passage des Déportés 2, 5030 Gembloux, Belgium

2 (IRSS/CNRST)/Department of Biomedical and Public Health, Institute of Health Sciences Research, Ouagadougou 03 BP 7192, Burkina Faso

3 Integrated and Urban Plant Pathology Laboratory, Gembloux Agro-Bio Tech, University of Liège, Passage des Déportés 2, 5030 Gembloux, Belgium

4 Laboratoire d'Entomologie Fondamentale et Appliquée, UFR/SVT, Université Joseph KI-ZERBO, Ouagadougou 03 BP 7021, Burkina Faso

\author{
Abbreviations \\ An. gambiae s.l Anopheles gambiae sensu lato \\ DNA Deoxyribonucleic acid \\ OTUs Operational taxonomic units \\ PCR Polymerase chain reaction
}

\section{Introduction}

Anopheles gambiae s.l is a major vector of malaria in subSaharan Africa because it transmits Plasmodium falciparum parasites to humans, with ensuing severe forms of malaria [1]. In 2017, an estimated 219 million cases of malaria occurred worldwide, mostly in Africa (92\%), followed by South-East Asia (5\%) and the eastern Mediterranean region (2\%) [1]. In the absence of a vaccine, malaria prevention heavily relies on vector control by insecticide-treated bed nets (LLINs) and indoor residual spraying (IRS) [2]. Nevertheless, in Africa this control is threatened by the rise of 
insecticide resistance in Anopheles mosquitoes [3], so that new strategies for malaria control are required [4]. The gut microbiota of mosquitoes plays an essential role in their susceptibility to Plasmodium falciparum, as demonstrated by previous studies [5]: the presence of antibiotics in the blood of malaria-infected people enhances the susceptibility of An. gambiae s.l to P. falciparum infection by disturbing their gut microbiota $[6,7]$. Therefore, the use of drugs or particular bacteria to disturb the microbiota of specific mosquitoes and affect their vector competence or fitness is a new concept that deserves further investigations [8]. Furthermore, the An. gambiae gut could be often a selective eco-environment (Proteobacteria and Bacteroidetes) [9]. Symbiotic control (paratransgenesis) is an alternative method for human disease vector control [10], and consists of genetic engineering of a symbiotic microorganism to alter the capacity of the mosquito to transmit malaria [11]. This control approach aims to limit or stop the development of the parasite in the mosquito vector [12] based on an understanding of the interactions between the vector, its environment, and the pathogen [13]. This approach provides antidisease strategies inside the mosquito hosts by harnessing their symbiotic microbes [14]. Mosquitoes are indeed continuously exposed to a variety of microorganisms, mainly bacteria from their ecosystem [15]. The microbial communities -also called microbiota-hosted by mosquitoes have been characterized by conventional culture methods $[16$, 17], by flow cytometry analysis [18], by shotgun metagenomic sequencing [19], or by amplicon sequencing of $16 \mathrm{~S}$ rRNA $[8,20,21]$. These methods showed that the microbiota can modulate the immune response of mosquitoes and their ability to influence human pathogen transmission $[5,15,22]$. Changes in the microbiota limit the development of the malaria parasite in Anopheles [23, 24]. A recent study showed that the Enterobacter genus directly blocked the development of the malaria parasite by producing free radicals harmful to Plasmodium sp. in the mosquito gut. This resulted in $99 \%$ resistance of An. gambiae s.l to infection by P. falciparum [23]. The suppression of the majority of midgut bacteria increased the susceptibility of $A n$. gambiae s.l and Aedes aegypti to infection by P. falciparum and the dengue fever virus, respectively [15]. This suggests that interactions between microbes and parasites reduce Plasmodium sp. transmission [25]. Decreasing the vector's transmission efficacy by modifying its microbiota is a very active and novel field of research [8, 26]. For instance, some bacteria such as Pantoea spp. and Asaia spp. are currently emerging as promising candidates for paratransgenesis [8, $27,28]$. These two genera have a high vertical transmission potential through multiple mechanisms. They are capable of horizontal infection through feeding and through mating in adult mosquitoes, indicating that they could quickly spread among natural mosquito populations [14]. The investigation of the An. gambiae s.l midgut microbiota may therefore be a promising way for further developing novel, safe, and effective strategies to manipulate the vectorial capacity [21, 26] and could promote new control methods [29, 30]. For example, the recent evolution of mosquito control involves mosquitoes genetically modified by gene drive [30]. This gene drive can generate a new phenotype which could modulate a midgut bacterial community to be hostile to Plasmodium transmission. However, any release of laboratory-modified mosquitoes in the wild will first require characterizing local mosquito populations. Burkina Faso is divided into three agroclimatic zones with different malaria epidemiological characteristics, i.e., the Sahelian area (short transmission period lasting 2 to 3 months), the Sudano-Sahelian area (seasonal transmission lasting 4 to 6 months) and the Sudanian area (perennial transmission) $[31,32]$. We investigated bacterial diversity in the microbiota of the An. gambiae complex in different locations of the country according to different ecological settings.

\section{Materials and methods}

\section{Mosquito collection and identification}

All mosquitoes were collected from human residential areas (indoors and outdoors) using a Prokopack aspirator (craft manufacturing) between August and October 2017. Three agroclimatic areas were surveyed: Sahelian, Sudano-Sahelian and Sudanian, with two localities per climatic area, one in a cotton-growing field (highly exposed to insecticides) and one away from cotton fields (unexposed to insecticides). For each locality, three sites were sampled except in the Sudanian area where only two sites were sampled from the cotton fields (Table 1).

The Sudanian climatic area (yearly rainfall $>900 \mathrm{~mm}$; average annual temperature $31^{\circ} \mathrm{C}$ ) has malaria transmission all year round. In the Sudano-Sahelian area (yearly rainfall between 600 and $900 \mathrm{~mm}$; average annual temperature $33{ }^{\circ} \mathrm{C}$ ), and the Sahelian area (yearly rainfall $<600 \mathrm{~mm}$; average annual temperature $35{ }^{\circ} \mathrm{C}$ ), malaria transmission is seasonal, with time periods of 4 to 6 months and 2 to 3 months, respectively [33]. From indoors and outdoors of houses, a total of 340 females of the An. gambiae complex with no blood in their midgut were selected and dissected under a light binocular microscope (Leica EZ4, magnification: $\times 10$ ) and grouped in 17 pools (one pool per site). Each pool included 20 individual females per site for each locality, field and zone (Table 1). 
Table 1 Location and sites surveyed for An. gambiae s.l mosquito samples

\begin{tabular}{|c|c|c|c|c|c|}
\hline No. & Fields & Localities & Sites & \multicolumn{2}{|c|}{ Geo-coordinates of the localities } \\
\hline \multicolumn{6}{|c|}{ Sahelian area } \\
\hline 1 & Cotton-growing & Kongoussi & Keilla, Rollo, Toessin & $13^{\circ} 19^{\prime} 31.063^{\prime \prime} \mathrm{N}$ & $-1^{\circ} 31^{\prime} 32.535^{\prime \prime} \mathrm{W}$ \\
\hline 2 & Cotton-free & Ouahigouya & Bissiguin, Yipala, Namsiguima & $13^{\circ} 34^{\prime} 0.573^{\prime \prime} \mathrm{N}$ & $-2^{\circ} 24^{\prime} 39.566^{\prime \prime} \mathrm{W}$ \\
\hline \multicolumn{6}{|c|}{ Sudano-Sahelian area } \\
\hline 3 & Cotton-growing & Kombissiri & Kosmasson, Zemtoega, Gomsi & $12^{\circ} 4^{\prime} 27.57^{\prime \prime} \mathrm{N}$ & $-1^{\circ} 20^{\prime} 31.571^{\prime \prime} \mathrm{W}$ \\
\hline 4 & Cotton-free & Réo & Seboun, Réo Sect. 7, Vour & $12^{\circ} 19^{\prime} 5.32^{\prime \prime} \mathrm{N}$ & $-2^{\circ} 27^{\prime} 55.295^{\prime \prime} \mathrm{W}$ \\
\hline \multicolumn{6}{|c|}{ Sudanian area } \\
\hline 5 & Cotton-growing & Houndé & Kohofabio, Yabiro, Kohobié & $11^{\circ} 29^{\prime} 21.926^{\prime \prime} \mathrm{N}$ & $-3^{\circ} 31^{\prime} 23.131^{\prime \prime} \mathrm{W}$ \\
\hline 6 & Cotton-free & Bobo & Koumi, Samagan/Logofrousso & $11^{\circ} 9^{\prime} 53.719^{\prime \prime} \mathrm{N}$ & $-4^{\circ} 18^{\prime} 18.555^{\prime \prime} \mathrm{W}$ \\
\hline
\end{tabular}

\section{Mosquito dissection}

All mosquitoes samples were identified morphologically as the Anopheles gambiae sensu lato (s.1) complex according to the identification keys of Gillies et al. [34, 35]. Living mosquitoes were anesthetized with chloroform, and dissected under sterile conditions. Three hundred and forty non-bloodengorged females were selected for dissection. The mosquitoes were surface sterilized twice prior to dissection by washing with $70 \%$ ethanol for $5 \mathrm{~min}$ and rinsing in a sterile saline phosphate buffer (PBS $1 \times, \mathrm{pH} 7.8$ ) [36]. Dissections were performed under a light binocular microscope (Leica EZ4, magnification: $\times 10$ ). Each mosquito gut was pulled out into a drop of sterile PBS $1 \times, \mathrm{pH} 7.8$ on a sterilized microscope slide. The guts were pooled (20 individual guts per site) into a sterile $1.5 \mathrm{~mL}$ Eppendorf tube containing $500 \mu \mathrm{L}$ of RNAlater (QIAGEN, USA), and stored at $-20^{\circ} \mathrm{C}$. The samples were brought to Gembloux Agro-Bio Tech, Functional \& Evolutionary Entomology laboratory (Gembloux, Belgium) and stored at $-80{ }^{\circ} \mathrm{C}$ till DNA extraction.

\section{DNA extraction and Illumina PCR amplicons}

Midgut DNA was extracted with a QIAamp DNA Micro Kit (QIAGEN, Valencia, CA) according to the manufacturer's instructions. Briefly, the samples were crushed individually with plastic pestles in $1.5-\mathrm{mL}$ tubes containing $180 \mu \mathrm{L}$ of ATL buffer, and $20 \mu \mathrm{L}$ of proteinase $\mathrm{K}$ were added. The mixtures were vortexed thoroughly and incubated overnight in a thermomixer $\left(56{ }^{\circ} \mathrm{C}, 450 \mathrm{rpm}\right)$. After processing and washing with the adequate products provided in the kit, the final DNA product was eluted using $20 \mu \mathrm{L}$ of AE elution buffer and stored at $-20{ }^{\circ} \mathrm{C}$ until PCR analysis. Surfaces were cleaned with $70 \%$ ethanol, and all extractions were performed under a localized aseptic microenvironment provided by flame from a Bunsen burner.

DNA concentrations were normalized at 5-6 ng/ $\mu \mathrm{L}$ with a Nanodrop spectrophotometer ND1000 V3.8.1 (Nanodrop, Wilmington, DE, United States) and stored at $-20^{\circ} \mathrm{C}$ before
Illumina Miseq $(2 \times 250 \mathrm{nt})$ library preparation. $16 \mathrm{~S}$ rRNA gene libraries were generated by targeting the v3-v4 universal region of the $16 \mathrm{~S}$ rRNA gene using the Illumina Miseq metagenomic sequencing library protocols and the 16S rRNA primers: 16S Amplicon PCR Forward Primer: 5' TCGTCGGCAGCGTCAGATGTGTATAAGAGACAGCCT ACGGGNGGCWGCAG and 16S Amplicon PCR Reverse Primer: 5' GTCTCGTGGGCTCGGAGATGTGTATAAGAG ACAGGACTACHVGGGTATCTAATC. The total volume of the PCR mix was $25 \mu \mathrm{L}$, containing $12.5 \mu \mathrm{L}$ of $2 \times$ KAPA HiFi HotStart ReadyMix, $5 \mu \mathrm{M}$ of each primer and $2.5 \mu \mathrm{L}$ of mosquito DNA templates. The PCR reaction was performed with the following temperatures: $95{ }^{\circ} \mathrm{C}$ for $3 \mathrm{~min}, 25$ cycles of $95{ }^{\circ} \mathrm{C}$ for $30 \mathrm{~s}, 55^{\circ} \mathrm{C}$ for $30 \mathrm{~s}$ and $72{ }^{\circ} \mathrm{C}$ for $30 \mathrm{~s}$; a final elongation step at $72{ }^{\circ} \mathrm{C}$ for $5 \mathrm{~min}$, and a storage temperature of $4{ }^{\circ} \mathrm{C}$. Five $\mu \mathrm{L}$ of PCR amplicons were loaded in $1 \%$ electrophoresis gel and visualized under UV light to check if the expected 450-bp band was obtained. The PCR products were then sent to DNAVision sequencing center (Gosselies, Belgium) for sequencing.

\section{Bioinformatics}

Demultiplexed quality-filtered reads obtained by IlluminaSeq from the sequencing center (forward and reverse) were processed using QIIME (Quantitative Insights Into Microbial Ecology) 1.9.0 version [37]. Each sample read was paired using the multiple_join_paired_ends.py script. Then paired fastq files were converted into fasta form with the script convert_fastaqual_fastq.py, and Qiime labels were added to these fasta files using the add_qiime_labels.py script with a valid metadata file.

Operational taxonomic units (OTUs) were picked with pick_open_reference_otus.py script using SILVA database (release 132) [38, 39] at 97\% similarity. The OTU table was cleaned by removing sequences corresponding to cytoplasmic (mitochondrial) contamination with the filter_taxa_ from_otu_table.py script. Then, the compute_core_diversity.py script was launched at 19,495 rarefaction depth for 
diversity analysis and sample comparison (beta diversity, OTU taxonomy summary and Kruskal-Wallis test). Alpha diversity indexes and their comparison were computed in $\mathrm{R}$, using Phyloseq package [40]. Heatmap trees of OTUs differential abundances and Wilcoxon Rank Sum were generated with the Metacoder R package [41].

\section{Results}

\section{Analysis of bacterial diversity at the phylum level}

A total of 718,556 sequences were generated from 17 samples (one site $=$ one sample). The average number of raw sequence reads per sample was 42,268 $\pm 64,695$ (between 19,495 and 300,529 reads). The generated sequences were assigned to 1676 OTUs. A plot of rarefication curves was estimated for each sample. The rarefaction depth of 19,495 sequences per sample was sufficient to obtain good estimates of OTU richness (Supplementary Material, Figs. A1 and A2).

A total of 17 bacterial phyla was found among all samples. The most dominant one was Proteobacteria (97.2\%), followed by Firmicutes (1.0\%), Bacteroidetes (1.0\%), and Actinobacteria $(0.2 \%)$. Altogether these 4 phyla accounted for $94-99 \%$ of the total OTUs (Fig. 1), while the other 13 phyla ranged between 1 and 6\%. By order of abundance, these minor phyla included Spirochaetes, Chloroflexi, Acidobacteria, Patescibacteria, Deinococcus-Thermus, Cyanobacteria, Armatimonadetes, Chlamydiae, Epsilonbacteraeota, Gemmatimonadetes, Halanaerobiaeota, Planctomycetes, and Verrucomicrobia. The numbers of phyla were distributed according to the climatic areas or cotton fields as follows: the Sahelian group contained 10 phyla (Kongoussi and Ouahigouya harbored 10 and 7 phyla, respectively), the Sudano-Sahelian group contained

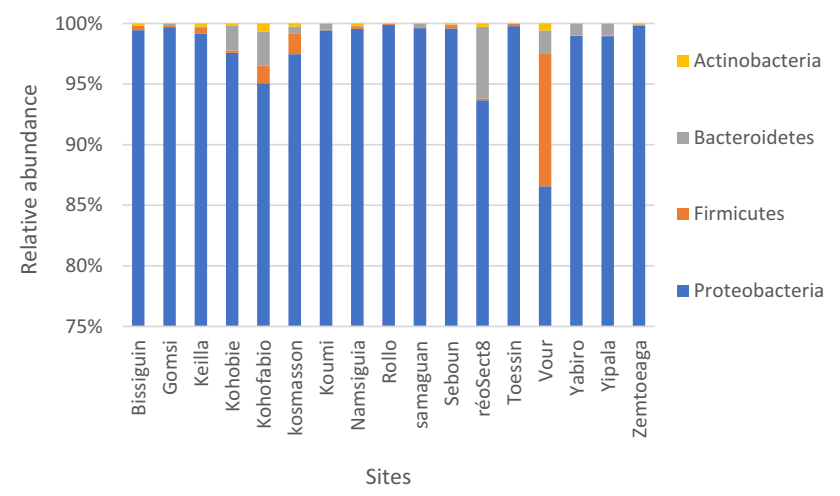

Fig. 1 Relative proportions of OTUs at the phylum level in all 17 samples (sites). Each bar represents one site, and each color stands for one phylum. Only the 4 major phyla (94-99\% of the total sequences) are presented for the sake of clarity. (Color figure online)
14 phyla (Kombissiri and Réo harbored 7 and 14 phyla, respectively), the Sudanian group contained 8 phyla (Bobo and Houndé harbored 5 and 7 phyla, respectively), the cotton-growing field harbored 12 phyla, and the cottonfree field harbored 16 phyla.

\section{Description of the core microbiome at the genus level}

Out of the assigned 1676 OTUs, 14 represented $19.51 \%$ of the reads (total sequences), 22 represented $76.74 \%$ of the sequences, and 125 represented $87.65 \%$ of the sequences. These 14, 22 and 125 OTUs were found in $100 \%, 90 \%$ and $50 \%$ of the samples, respectively. The bacteria found in all samples belonged to 33 classes, 73 orders, 125 families and 224 genera. The most 20 bacterial genera $(98.44 \%$ of total OTUs at the genus level) are presented in Fig. 2. The most dominant genus was Enterobacter (32.8\% of OTUs), followed by Aeromonas (29.8\%), Pseudomonas (11.8\%), Acinetobacter (5.9\%) and Thorsellia (2.2\%).

A Venn diagram analysis of overlapping genera per area showed that 166, 155 and 128 genera were found in the Sahelian, Sudanian and Sudano-Sahelian areas, respectively, while 208 and 231 genera were detected in the cotton-growing and cotton-free fields respectively (Fig. 3). As regards climatic areas, 91 (30.4\%) genera were common to all three areas, $22(7.4 \%)$ were in common between the SudanoSahelian and Sahelian areas, 10 (3.3\%) were in common between the Sahelian and Sudanian areas, and 26 (8.7\%) were in common between the Sudanian and Sudano-Sahelian areas. In the cotton-related fields, $140(46.8 \%)$ were in common between the cotton-growing and cotton-free fields. This suggests that $30.4 \%$ of the bacteria belonged to the three climatic zones, while $46.8 \%$ were in common between the cotton-growing and cotton-free areas.

\section{Differential abundance of the taxonomic profiles}

The Kruskal-Wallis test showed no significant difference (FDR $-p>0.05$ ) in the distribution at the genus level according to the climate or cotton areas. However, the Wilcoxon Rank Sum test highlighted differential abundances in the OTUs assigned at the genus level across our samples. The site of Réo (a cotton-free field) harbored OTUs with higher abundances (Fig. 4a). A similar trend was observed when comparing the differential abundances among the climatic zones or between the cotton-growing fields in the Sudano-Sahelian area (Fig. 4b) and the cotton-free field (Fig. 4c), which displayed the highest median abundances of OTUs at the genus level. 
Fig. 2 Pie chart of the predominant genera $(98.44 \%$ of total OTUs) of Anopheles gambiae Anopheles gambiae s.l gut microbiota diversity at the genus level. Each color represents one genus, and the most abundant ones are represented from top to bottom. (Color figure online)

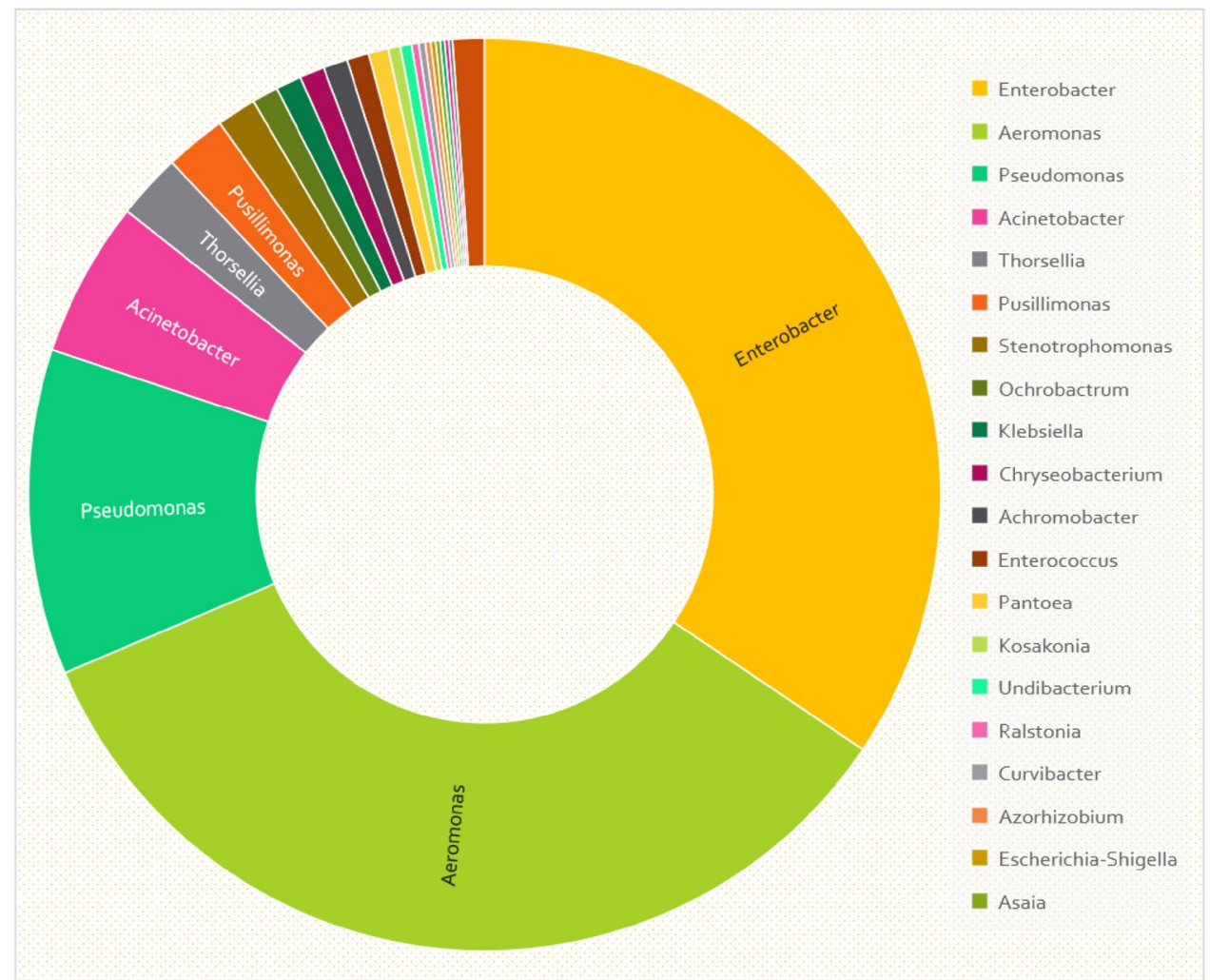

Fig. 3 Venn diagrams of the analysis of shared genera. a Climatic areas, $\mathbf{b}$ cotton-related fields

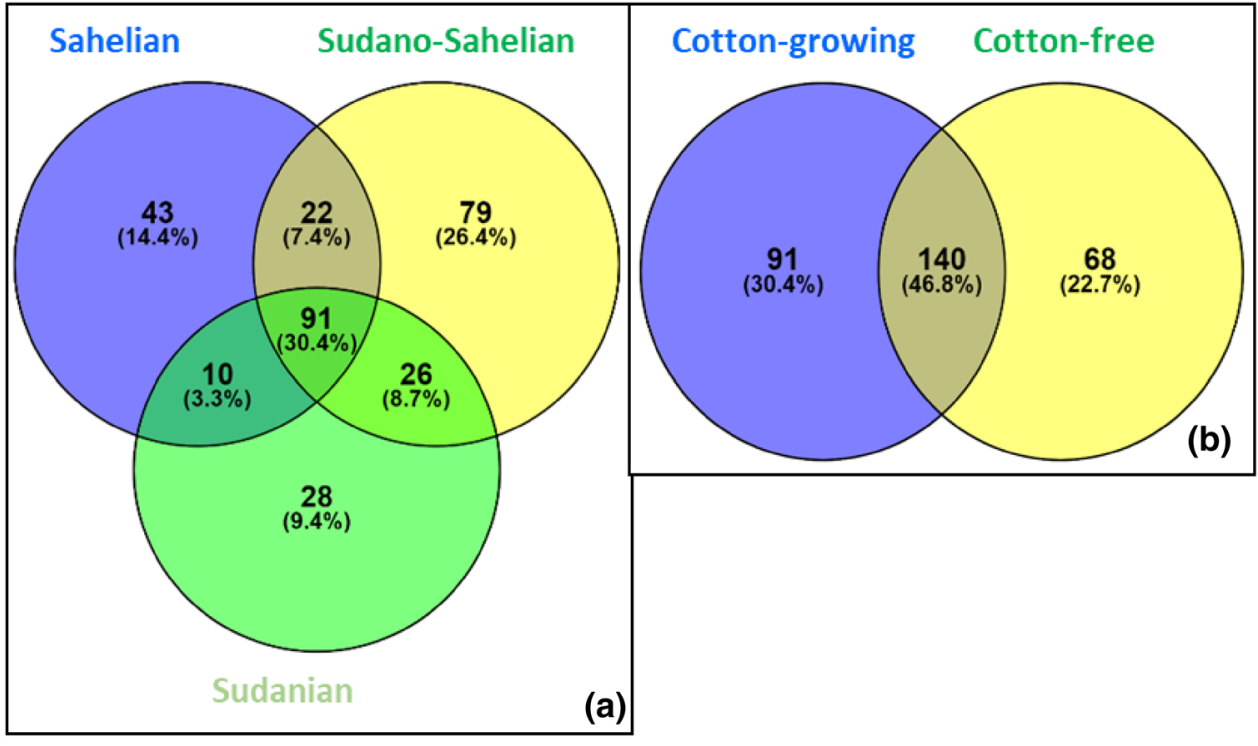

\section{Bacterial community richness and diversity}

Richness estimators (observed OTUs and Chao1) and diversity indexes (Shannon and Simpson) were calculated. Observed OTUs, Chao1, Simpson and Shannon indexes indicated a significant difference $(p<0.05)$ between cotton-growing and cotton-free fields per site in the Sudano-Sahelian climatic area (Fig. 5). In fact, in that area, the cotton-free field of Réo was the richest and most diverse site as compared to the cotton-growing field of Kombissiri. The comparison of the alpha diversity indexes of the three climatic areas in each category of cotton field did not evidence any significant difference (Supplementary material A4). 


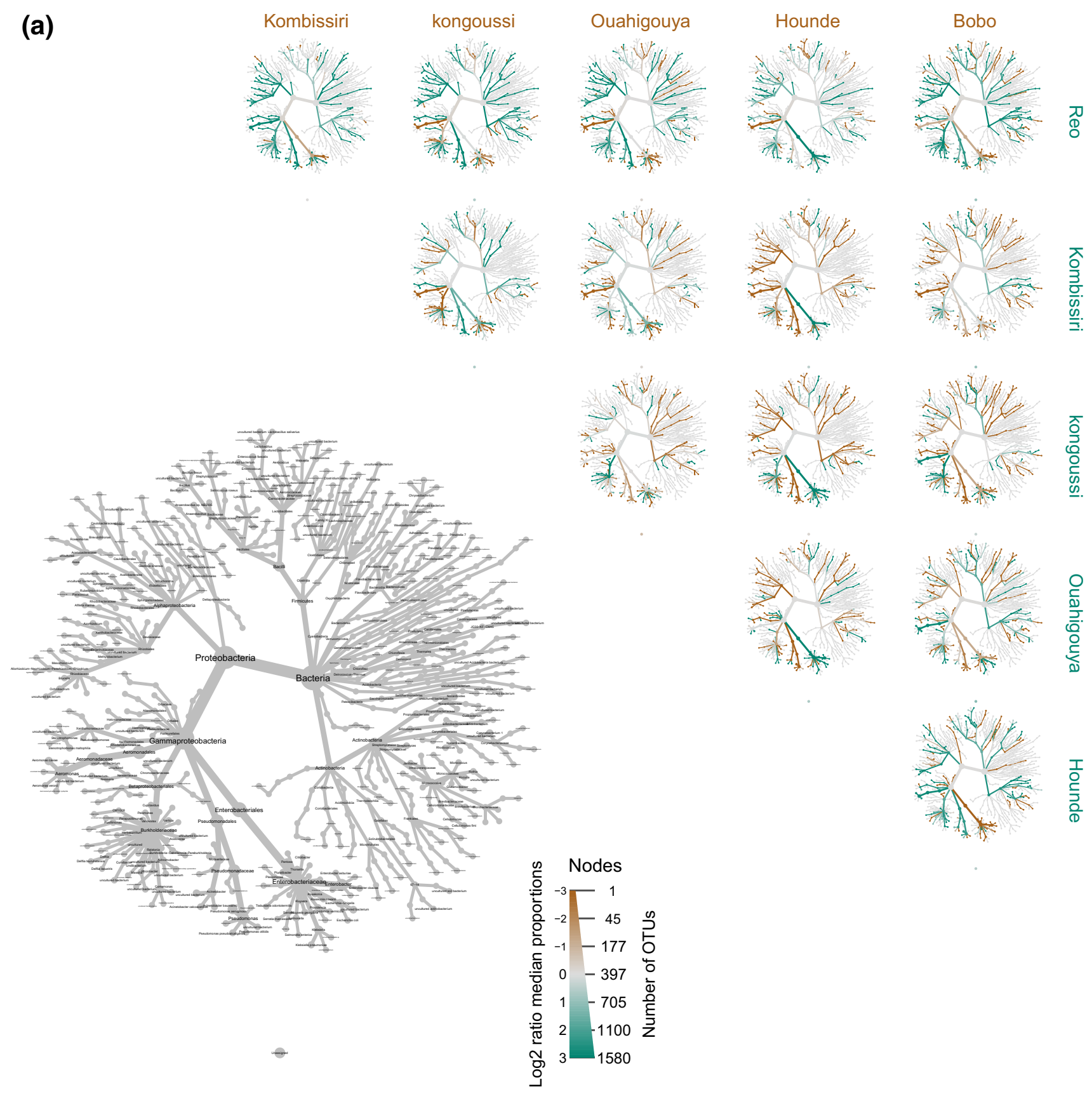

Fig. 4 a Heatmap tree of the median relative abundance tree per site. b Heatmap tree of the median relative abundance tree per climatic area. $\mathbf{c}$ Heatmap tree of the median relative abundance tree per cotton-growing or cotton-free field. Pairwise comparisons were made between the samples in the columns (brown) and the samples in the rows (blue) for all figures; each node shows one OTU, and its size is proportional to the number of reads; the node colors represent the differences in the median proportions of the $\log 2$ ratios of the reads; the brown color shows a greater abundance of OTUs in the samples represented in the columns, and the blue color shows a greater abundance of OTUs in the samples represented in the rows. The deeper the color, the higher the OTU abundance. In figure c, samples from the cotton-growing field are highlighted in blue and samples from the cotton-free field are highlighted in brown. For figures $\mathbf{a}$ and $\mathbf{b}$, the trees in tan color are annotated trees of the shared OTUs across all samples. (Color figure online) 
(b)
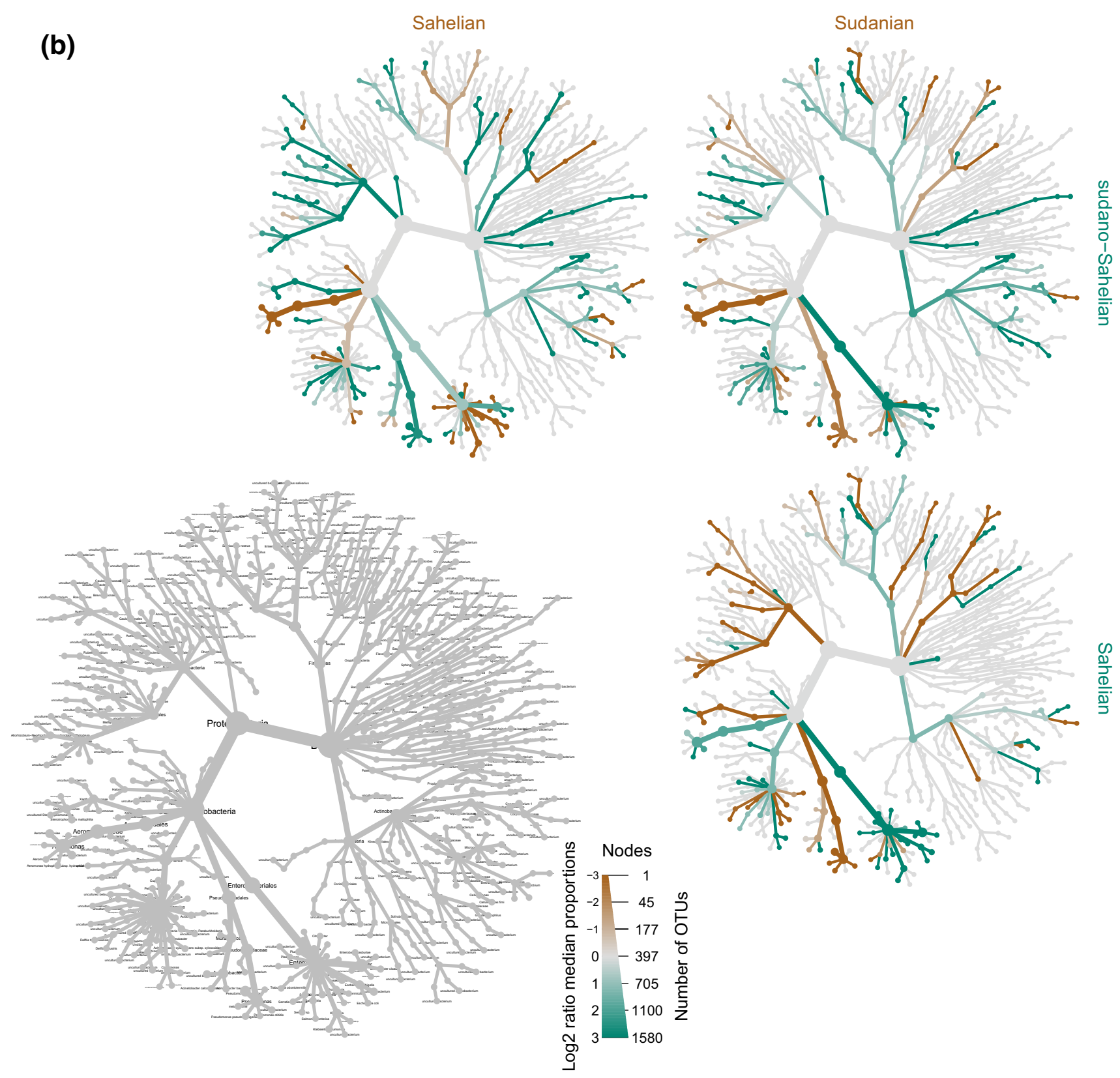

Fig. 4 (continued)

\section{Beta-diversity analysis: microbial community structure in the midgut of mosquitoes from the Anopheles gambiae s.I}

Our weighted UniFrac distances plotted in PCoA (Fig. 6) showed no cluster of samples, suggesting that the bacterial microbiota of the midgut of An. gambiae s.l was similar (Adonis PERMANOVA test, $p>0.05$ ) across Burkina Faso.

\section{Midgut microbiota of Anopheles gambiae s.l and interactions with Plasmodium infection}

Based on the core microbiota description, we analyzed eight (8) genera that negatively interacted with Plasmodium spp. infection in An. gambiae s.1 [8, 42]. The most abundant genus was Aeromonas, followed by Enterobacter, Pseudomonas, Klebsiella, Pantoea, Asaia, Serratia and Comamonas, whatever the climatic area or the presence or absence of cotton fields (Table 2). No significant difference was evidenced among these genera (FDR $-p>0.05$ ). Nevertheless, contrasted differential abundances of some genera were observed, 


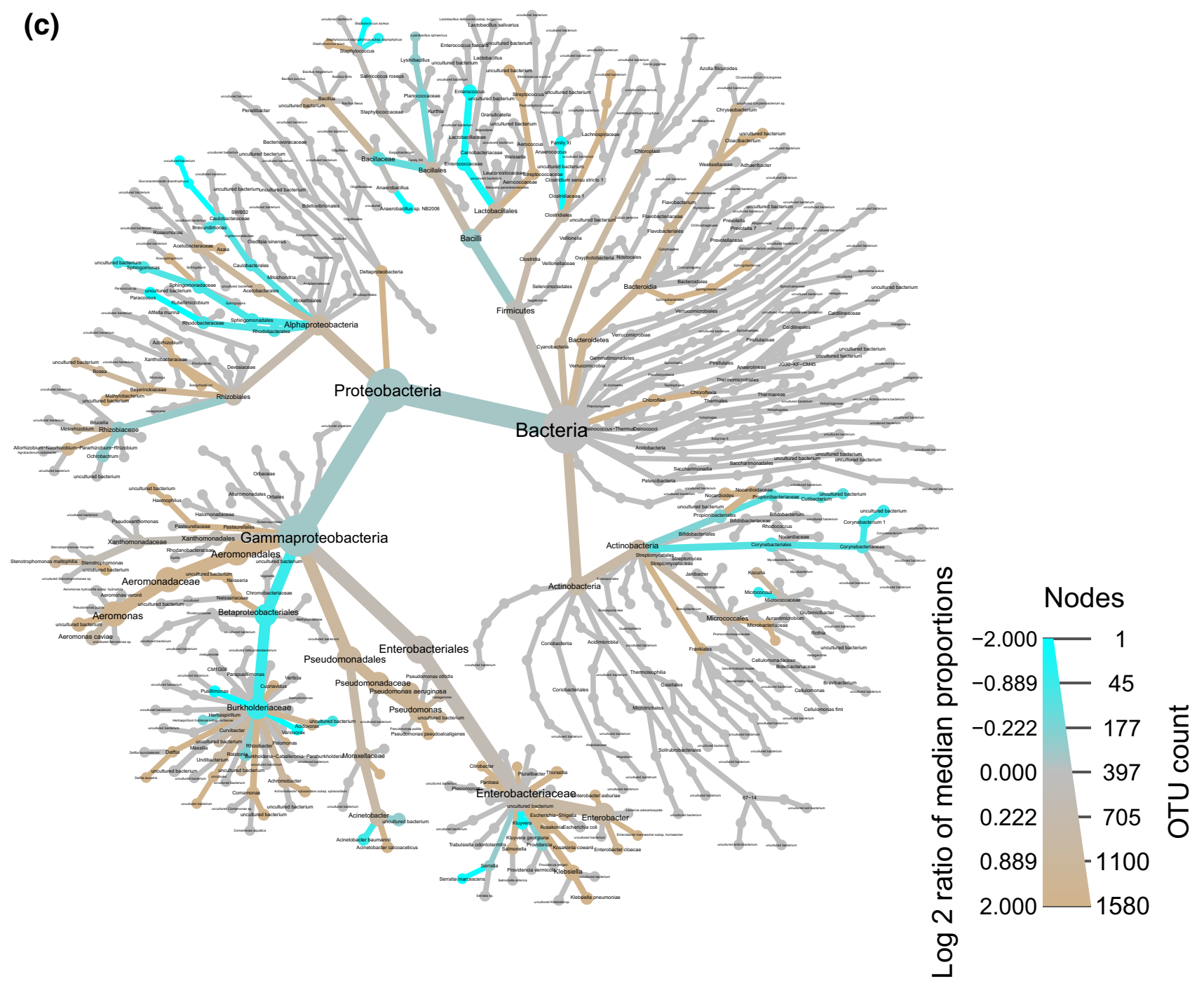

Fig. 4 (continued)

mostly for Aeromonas, e.g., in the Sudano-Sahelian area as compared to the Sahelian area. Rarefied abundances of these species and the situation of malaria in the areas surveyed in this study is shown in Table 2.

\section{Discussion}

Our study characterizes the microbiota of An. gambiae s.l females from different ecological areas that vary according to climatic conditions and to the presence or absence of cotton fields. The phylum Proteobacteria was predominant (97.2\% of total sequences) followed by Firmicutes, Bacteroidetes and Actinobacteria. Other studies carried out at the phylum level found that Proteobacteria were often the most diverse and common among An. gambiae s.1 [15, 21]. In Vietnam, seven phyla from the Anopheles microbiota mostly belonged to Proteobacteria, Firmicutes and Actinobacteria [43]. In Kenya, Proteobacteria and Bacteroidetes dominated in An. gambiae s.l guts, with core taxa of Enterobacteriaceae and Flavobacteriaceae [9]. In our study, Enterobacteriaceae and Aeromonadaceae were the most abundant OTUs, while in another study the abundance of Enterobacteriaceae in the mosquito midgut significantly correlated negatively with the Plasmodium infection status [36]. In addition, other similar studies of other mosquito species such as Culex quinquefasciatus, Aedes albopictus and Aedes aegypti showed that Proteobacteria appeared to be the most dominant phylum [21, 30, 40, 42, 43].

Furthermore, at the genus level, Enterobacter was the most dominant genus in our samples, followed by Aeromonas, Pseudomonas, Acinetobacter, Thorsellia, down to Asaia. Among the five most common genera, Thorsellia was the only one found only in vector mosquitoes. This 


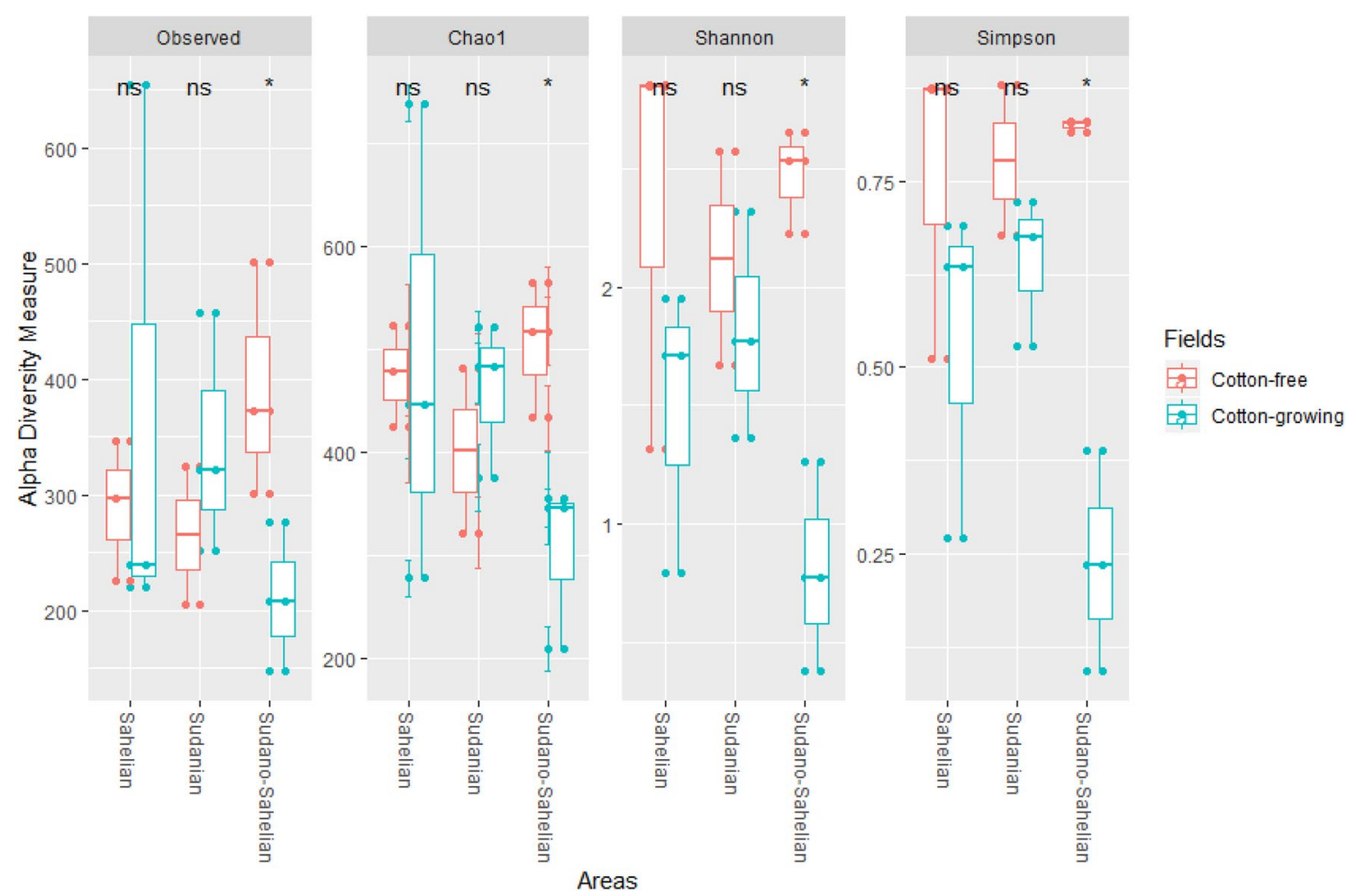

Fig. 5 Comparison of the richness and diversity of the bacterial communities harbored by Anopheles gambiae s.l in Burkina Faso according to climatic areas; ns: not significant; *statistically significant $(p<0.05)$

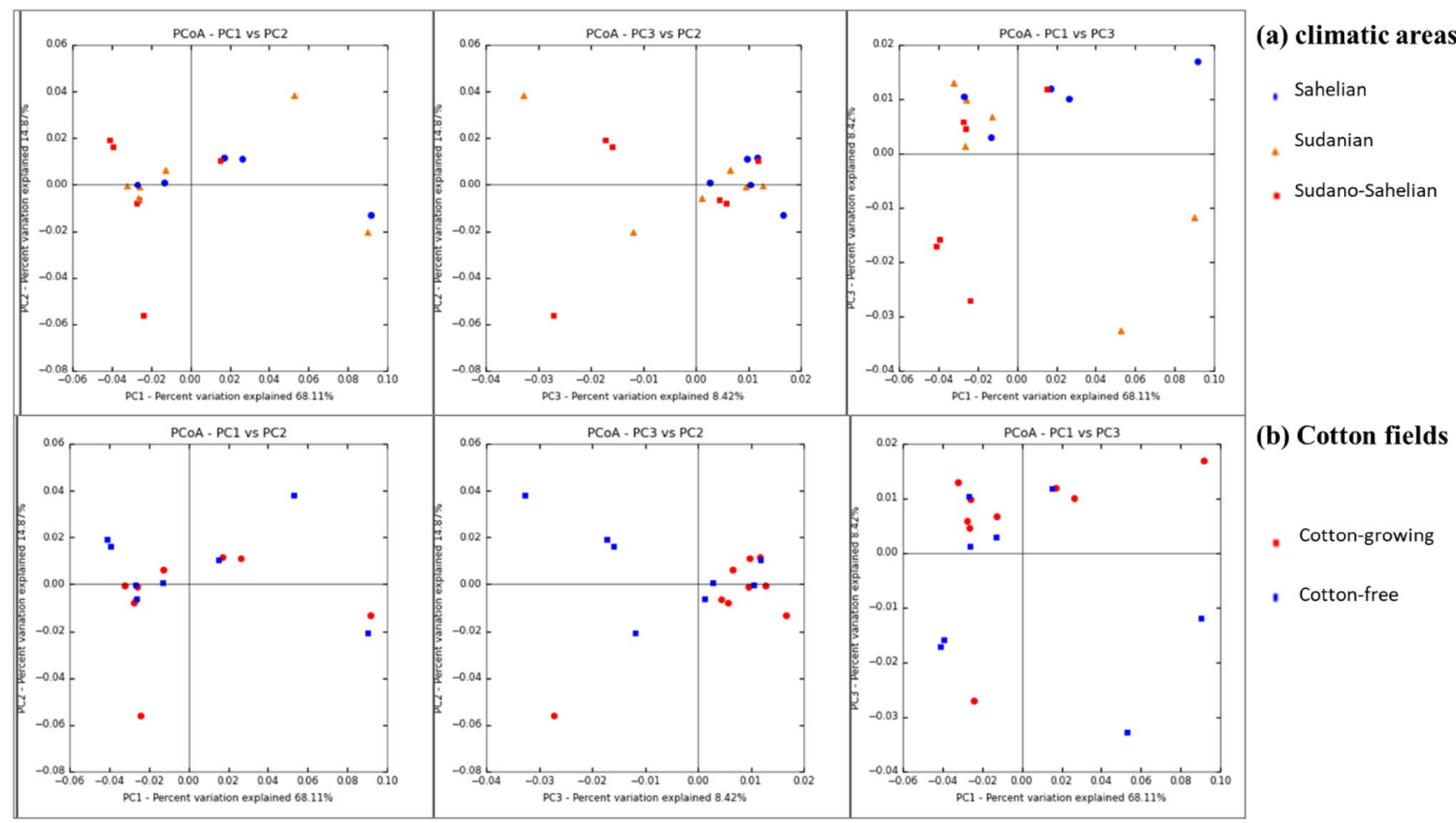

Fig. 6 2D principal coordinate analysis (PCoA) plots of the weighted UniFrac distances of Anopheles gambiae s.l midgut bacterial diversity according to a climatic areas and $\mathbf{b}$ the presence or absence of cotton fields. Each dot on the graph represents one sample. $P C$ principal coordinates 


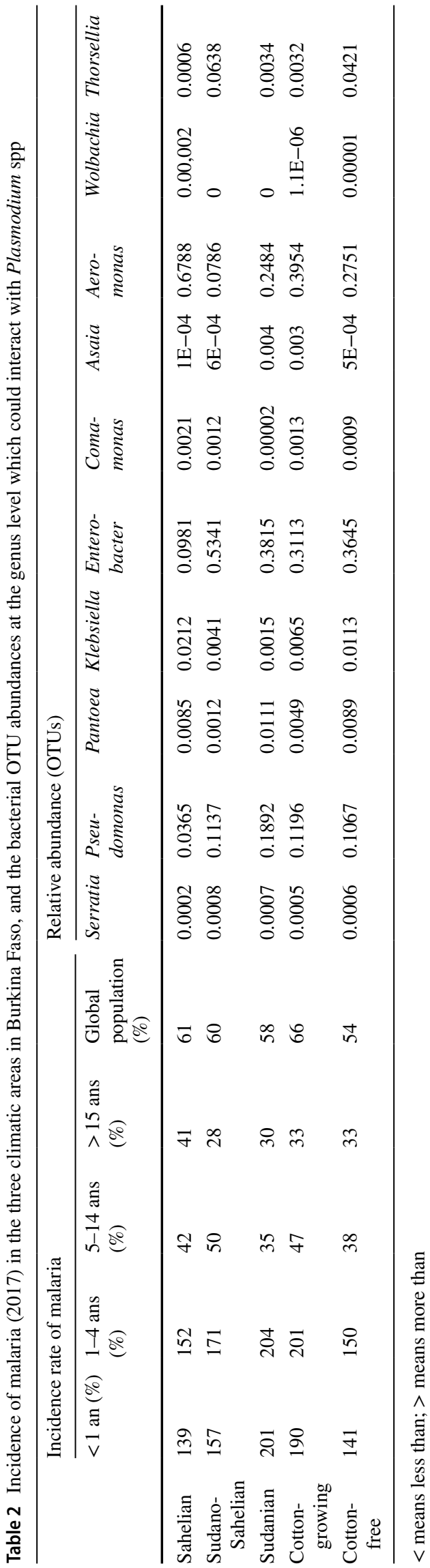

bacterium was first isolated from the midgut of An. arabiensis in 2006 [45], and has also been reported as predominant in the midgut of adult An. gambiae s.l. mosquitoes captured in dwellings in central Kenya [46] in temperate climate area. Table 2 shows also that Thorsellia was relatively more abundant in the Sudano-Sahelian area than in the other climatic areas (Sudanian and Sahelian).

Previous studies found Enterobacter and Serratia in Anopheles adults collected in the field [15, 21]. The Asaia genus was isolated in the midgut, salivary glands and reproductive organs of different wild and laboratory colonies of An. gambiae s.l from Burkina Faso [47]. Pantoea and Enterobacter were the most common genera identified in field An. gambiae s.l from Kenya and Mali [48]. In Cameroon, the midgut microbiota of An. gambiae s.l was composed of members of only one phylum, i.e., Proteobacteria, and dominated by Comanomas, Serratia, Pseudomonas, Burkolderia and Brevundimonas [49]. In Mali, the bacteria identified from An. gambiae s.l. were Escherichia, Salmonella, Klebsiella, Pseudomonas, Staphylococcus, and Shigella [50]. Furthermore, other studies outside Sub-Saharan Africa have shown similar results. For example, in Belgium, Acinetobacter, Pseudomonas, and Asaia were found in most mosquitoes, with a high prevalence of Pseudomonas in Anopheles [51], whereas in Vietnam the most prevalent genera were Staphylococcus, Clostridium, and Bacillus among Firmicutes [43]. The same study found that the Anopheles microbiota was greatly influenced by the local environment [43]. An. gambiae s.l collected in the field was also found to harbor low bacterial diversity, but significant differences were found in the core microbiota depending on the collection sites [35, 46]. Nevertheless, our results showed no significant difference in the core microbiota (abundance) among climatic areas and between cotton-growing or cotton-free fields. In contrast, richness indexes (observed, Chao1) and diversity indexes (Simpson and Shannon indexes) evidenced a significant difference in OTU richness and diversity at the genus level. The mosquitoes from the Sudano-Sahelian area hosted the highest numbers of OTUs, and so did the cottonfree fields (highest richness and diversity). This result could be explained by a greater richness of the microbiota in the Réo site than in the Kombissiri site. Moreover, Réo is a cotton-free field (Sudano-Sahelian area). Therefore, we can hypothesize a negative effect of cotton inputs such as insecticides on the bacterial richness and diversity of An. gambiae s.l midgut. The different environments are known to give each An. gambiae s.l specific bacterial profiles that provide precise and predictive information on the spatial dynamics of the population [53]. But no clustering was found from our UniFrac distance metrics plotted in the PCoA analysis, suggesting that Anopheles females share a similar bacterial community throughout Burkina Faso. The difference may be explained by the fact that the study by Buck et al. was 
performed on single whole mosquitoes of An. coluzzii, while our study was performed on pooled An. gambiae s.l of one body part (the midgut) in the whole of Burkina Faso.

We did not find any phylogenetic structuring of the Anopheles midgut bacterial community according to the climatic zone or to the presence or absence of cotton fields. This result provides the basis for a more in-depth study in which a paratransgenesis application on An. gambiae s.l should be experienced in Burkina Faso. In addition, we found greater relative richness and diversity of the microbiota in the cotton-growing fields than in the cotton-free fields. The role of the midgut microbiota in conferring insecticide resistance in mosquitoes is unclear, while the link with insecticide resistance in agricultural pests is established [54]. A recent study reported for the first time a link between the microbiota (Bacillus anthracis, B. cereus, B. thuringiensis) and phenotypic resistance to the insecticide fenitrothion in An. albimanus, suggesting that bacterial taxonomic richness confers mosquitoes a competitive advantage in response to insecticide selection pressure [55]. We found higher relative bacterial abundance in the cotton-free fields more than in the cotton-growing field. Assuming that the microbiota diversity in An. gambiae l.s may have a link with the susceptibility of insecticide, this result suggests that cotton-growing field mosquitoes have a less bacterial diversity, then, they should be more resistant to insecticides. In Burkina Faso, the active ingredients of formulations for cotton crop protection belong to four insecticide classes: pyrethroids, organochlorines, organophosphates and carbamates, all used by spraying [56]. Furthermore, resistance to these molecules used to control Anopheles has emerged in the country [57]. In Burkina Faso, pyrethroid resistance has increased in recent years [58] as the frequencies of the 1014F kdr mutation and high ace-1R in 15 sites in 3 climatic areas [60]. Also, in rice-growing fields that use insecticide as in cotton-growing, it is noticed a high level of frequency of kdr L1014F mutation and Ace-1R mutation in An. gambiae s.1 [61].

At the level of malaria transmission, $P$. falciparum is the most prevalent malaria parasite in $99.7 \%$ of cases in the African continent [1]. Knowing that some bacteria strongly influence malaria transmission, we hypothesized that the midgut microbiota of An. gambiae s.l reflected the bacterial community of the environment in which it lived and that this correlation could be one explanation for the environment-related epidemiological characteristics of malaria. Among the 224 bacterial genera detected, 8 of them genera had an An. gambiae s.l-Plasmodium interaction by reducing transmission to humans [8]. The most frequent genus was Pseudomonas, followed by Aeromonas, Asaia, Comamonas, Enterobacter, Klebsiella, Pantoea and Serratia [18, 44]. Table 2 shows greater abundance of OTUs from the genera Pantoea, Klebsiella, Aeromonas and Comamonas in the Sahelian area, of Asaia and Pseudomonas in the Sudanian area, and of Enterobacter in the Sudano-Sahelian area. All these genera (OTUs) were also more abundant in cottongrowing localities. Other studies showed that the abundance of the genera Serratia or Asaia was significantly correlated negatively with $P$. falciparum infection both in the midgut and salivary glands of malaria-vector mosquitoes [44, 50, 51]. Asaia, Enterobacter, Pantoea, Serratia and Pseudomonas have been proposed as promising symbiotic control agents of malaria vectors such as An. gambiae s.l by paratransgenesis [52, 53, 62]. Asaia is transmitted vertically from mother to progeny, indicating that it could quickly spread [14]. This great OTU abundance of natural microbes (Pantoea, Klebsiella, Aeromonas and Comamonas) which mediate refractoriness to Plasmodium infection in An. gambiae s.l [43], has been noticed in the Sahelian area where less pluviometry is recorded in Burkina Faso and thus could explain the low transmission rate [32]. These data (low malaria transmission region) are correlated with the statistics of the 2017-2018 report about National Malaria Indicators [63]. We found Wolbachia in An. gambiae s.l. It was also recently discovered in Burkina Faso, and the authors described it as a novel Wolbachia strain related to but distinct from strains infecting other arthropods [64]. Infection by this recent Wolbachia strain was negatively correlated with the presence of Plasmodium parasites [55, 56]. Wolbachia can manipulate mosquito reproduction and immunity and thus limit the spread of arthropod human pathogens [54, 57]. Wolbachia are obligate in filaria and are inherited intracellular bacterial endosymbionts colonizing around half of the insect species including several Culex and Aedes mosquito species [58, 59], but rarely found in Anopheles species [65]. Nevertheless, Wolbachia has also been found in An. gambiae s.l and An. moucheti from Guinea, the Democratic Republic of Congo, Ghana, Uganda, and Madagascar [66]. This evidence of Wolbachia presence promotes further investigations on the possible use of natural Wolbachia-Anopheles associations to limit malaria transmission [8].

\section{Conclusion}

This study explored the midgut bacterial community of $A n$. gambiae s.1, a malaria vector from Burkina Faso. No statistical difference in OTU abundances was found among the different areas, fields or localities. Therefore, the same control strategy to target mosquito midgut bacterial community and affect their fitness by bacterial refractoriness species to Plasmodium may be a valuable way for future malaria control efforts in Burkina Faso. Richness and diversity indexes showed significant differences in the cotton-growing fields and in the agroclimatic zones, mainly in the SudanoSahelian area. Potential bacterial species refractoriness to 
Plasmodium were detected, with a particular great abundance in the Sahelian area where low rate of malaria has been recorded.

Acknowledgements This work was funded by Islamic Development Bank (IDB) Merit Scholarship Program for High Technology. We are sincerely grateful to all the inhabitants of the mosquito collection villages for participating into this study. We also acknowledge the mosquito collectors (Mrs Tientiga Martin, Zouré Abdou Azaque and Somda Zéphirin.) and Mr Dramé Drissa who identified and dissected the mosquitoes, for their valuable contribution to the successful completion of the study.

Authors' contribution $\mathrm{AAZ}, \mathrm{AB}$ and FF conceived and designed the study. AAZ, ZS, FY and AB supervised the data and samples collection. AAZ and ARS performed practical work, analyzed, interpreted the results and wrote the manuscript. $\mathrm{AB}, \mathrm{SM}$ and FF revised the manuscript. All authors were the major contributors in writing the manuscript. All authors read and approved the final manuscript.

Data availability All data generated or analyzed during this study are included in this published article and its supplementary information files. Fastq reads were submitted and are available in the NCBI (National Center for Biotechnology Information) Sequence Read Archive (SRA) under BioProjectPRJNA558839.

\section{Compliance with ethical standards}

Conflict of interest The authors declare that they have no competing interests.

Ethics approval This study was approved by the National Health Ethic Committee (CERS) in Burkina Faso (reference number 2017-9-143 of 12 September 2017).

Informed consent For mosquito collection in residential areas, written informed and consent was obtained from homeowners in each location.

\section{References}

1. WHO (2018) World Malaria Report. World Health Organization, Geneva

2. Karunamoorthi K, Sabesan S (2013) Insecticide resistance in insect vectors of disease with special reference to mosquitoes: a potential threat to global public health. Heal Scope 2:4-18. https ://doi.org/10.17795/jhealthscope-9840

3. Hemingway J, Ranson H, Magill A et al (2016) Averting a malaria disaster: will insecticide resistance derail malaria control? Lancet 387:1785-1788. https://doi.org/10.1016/S0140-6736(15)00417-1

4. Hemingway J, Shretta R, Wells TNC et al (2016) Tools and strategies for malaria control and elimination: what do we need to achieve a grand convergence in malaria? PLoS Biol 14:e1002380. https://doi.org/10.1371/journal.pbio.1002380

5. Sharma A, Dhayal D, Singh OP et al (2013) Gut microbes influence fitness and malaria transmission potential of Asian malaria vector Anopheles stephensi. Acta Trop 128:41-47. https://doi. org/10.1016/j.actatropica.2013.06.008

6. Tchioffo MT, Boissière A, Churcher TS et al (2013) Modulation of malaria infection in Anopheles gambiae mosquitoes exposed to natural midgut bacteria. PLoS ONE 8:4-12. https://doi. org/10.1371/journal.pone.0081663
7. Gendrin M, Rodgers FH, Yerbanga RS et al (2015) Antibiotics in ingested human blood affect the mosquito microbiota and capacity to transmit malaria. Nat Commun 6:1-7. https://doi.org/10.1038/ ncomms6921

8. Gendrin M, Christophides GK (2013) The anopheles mosquito microbiota and their impact on pathogen transmission. Anopheles Mosquitoes. https://doi.org/10.5772/55107

9. Wang Y, Gilbreath TM 3rd, Kukutla P et al (2011) Dynamic gut microbiome across life history of the malaria mosquito Anopheles gambiae in Kenya. PLoS ONE 6:e24767. https:// doi.org/10.1371/journal.pone.0024767

10. Ricci I, Valzano M, Ulissi U et al (2012) Symbiotic control of mosquito borne disease. Pathog Glob Health 106:380-385. https ://doi.org/10.1179/2047773212Y.0000000051

11. Wang S, Jacobs-Lorena M (2013) Genetic approaches to interfere with malaria transmission by vector mosquitoes. Trends Biotechnol 2(31):185-193. https://doi.org/10.1016/j.tibte ch.2013.01.001.Genetic

12. Guerin PJ, Olliaro P, Nosten F, Druilhe P, Laxminarayan R, Fred Binka, Kilama WL, Ford N, White NL (2002) Malaria: current status of control, diagnosis, treatment, and a proposed agenda for research and development. LANCET Infect Dis 2:564-573. https://doi.org/10.1016/S1473-3099(02)00372-9

13. Engel P, Moran NA (2013) The gut microbiota of insectsdiversity in structure and function. FEMS Microbiol Rev 37:699-735. https://doi.org/10.1111/1574-6976.12025

14. Favia G, Ricci I, Marzorati M et al (2008) Bacteria of the genus Asaia: a potential paratransgenic weapon against malaria. In: Aksoy S (ed) Transgenesis and the management of vector-borne disease. Springer, New York, pp 49-59

15. Dennison NJ, Jupatanakul N, Dimopoulos G (2014) The mosquito microbiota influences vector competence for human pathogens. Curr Opin Insect Sci 3:6-13. https://doi.org/10.1016/j. cois.2014.07.004

16. Kim CH, Lampman RL, Muturi EJ (2015) Bacterial communities and midgut microbiota associated with mosquito populations from Waste Tires in East-Central Illinois. J Med Entomol 52:63-75. https://doi.org/10.1093/jme/tju011

17. Gonzalez-Ceron L, Santillan F, Rodriguez MH et al (2003) Bacteria in midguts of field-collected Anopheles albimanus block Plasmodium vivax sporogonic development. J Med Entomol 40:371-374. https://doi.org/10.1603/0022-2585-40.3.371

18. Habtewold T, Duchateau L, Christophides GK (2016) Flow cytometry analysis of the microbiota associated with the midguts of vector mosquitoes. Parasites Vectors 9:1-10. https://doi. org/10.1186/s13071-016-1438-0

19. Chandler JA, Liu RM, Bennett SN (2015) RNA shotgun metagenomic sequencing of Northern California (USA) mosquitoes uncovers viruses, bacteria, and fungi. Front Microbiol 6:1-16. https://doi.org/10.3389/fmicb.2015.00185

20. Lindh JM, Lindh JM, Terenius O et al (2005) 16S rRNA genebased identication of midgut bacteria from field-caught. Appl Environ Microbiol 71:7217-7223. https://doi.org/10.1128/ AEM.71.11.7217

21. Yadav KK, Bora A, Datta S et al (2015) Molecular characterization of midgut microbiota of Aedes albopictus and Aedes aegypti from Arunachal Pradesh, India. Parasites Vectors 8:1-8. https://doi.org/10.1186/s13071-015-1252-0

22. Aguilar R, Dong Y, Warr E, Dimopoulos G (2005) Anopheles infection responses: laboratory models versus field malaria transmission systems. Acta Trop 95:285-291. https://doi. org/10.1016/j.actatropica.2005.06.005

23. Dong Y, Manfredini F, Dimopoulos G (2009) Implication of the mosquito midgut microbiota in the defense against malaria parasites. PLoS Pathog. https://doi.org/10.1371/journal.ppat.10004 23 
24. Cirimotich CM, Dong Y, Garver LS et al (2010) Mosquito immune defenses against Plasmodium infection. Dev Comp Immunol 34:387-395. https://doi.org/10.1016/j.dci.2009.12.005

25. Alavi Y, Arai M, Mendoza J et al (2003) The dynamics of interactions between Plasmodium and the mosquito: a study of the infectivity of Plasmodium berghei and Plasmodium gallinaceum, and their transmission by Anopheles stephensi, Anopheles gambiae and Aedes aegypti. Int J Parasitol 33:933-943. https://doi. org/10.1016/S0020-7519(03)00112-7

26. Hegde S, Rasgon JL, Hughes GL (2015) The microbiome modulates arbovirus transmission in mosquitoes. Curr Opin Virol 15:97-102. https://doi.org/10.1016/j.coviro.2015.08.011

27. Mancini MV, Spaccapelo R, Damiani C et al (2016) Paratransgenesis to control malaria vectors: a semi-field pilot study. Parasites Vectors 9:1-9. https://doi.org/10.1186/s13071-016-1427-3

28. Ricci I, Damiani C, Capone A et al (2012) Mosquito/microbiota interactions: from complex relationships to biotechnological perspectives. Curr Opin Microbiol 15:278-284. https://doi. org/10.1016/j.mib.2012.03.004

29. Minard G, Mavingui P, Moro CV (2013) Diversity and function of bacterial microbiota in the mosquito holobiont. Parasites Vectors 6:1. https://doi.org/10.1186/1756-3305-6-146

30. Kyrou K, Hammond AM, Galizi R et al (2018) OPEN A CRISPR-Cas9 gene drive targeting doublesex causes complete population suppression in caged Anopheles gambiae mosquitoes. Nat Biotechnol. https://doi.org/10.1038/nbt.4245

31. Abiodun GJ, Maharaj R, Witbooi P, Okosun KO (2016) Modelling the influence of temperature and rainfall on the population dynamics of Anopheles arabiensis. Malar J 15:1-15. https://doi. org/10.1186/s12936-016-1411-6

32. Kabore B, Kam S, Ouedraogo GWP, Bathiebo DJ (2017) Etude de l'évolution climatique au Burkina Faso de 1983 à 2012: cas des villes de Bobo dioulasso, Ouagadougou et Dori. Arab J Earth Sci 4:50-59

33. Ministère de la Santé du Burkina Faso (2018) Annuaire statistique 2017. Direction, Ouagadougou

34. Gillies MT, Meillon DB (1968) The Anophelinae of Africa south of the Sahara (Ethiopian Zoogeographical Region). South African Institute for Medical Research, Johannesburg

35. Gillies MT, Coetzee M (1987) A supplement to the Anophelinae of Africa South of the Sahara. Publ South African Inst Med Res 55:63. https://doi.org/10.1046/j.1365-294X.1997.00177.x

36. Boissiere A, Tchioffo MT, Bachar D et al (2012) Midgut microbiota of the malaria mosquito vector Anopheles gambiae and interactions with Plasmodium falciparum infection. PLoS Pathog 8:e1002742. https://doi.org/10.1371/journal.ppat.1002742

37. Caporaso JG, Kuczynski J, Stombaugh J et al (2010) QIIME allows analysis of high-throughput community sequencing data. Nat Methods 7:335-336. https://doi.org/10.1038/nmeth.f.303

38. Pruesse E, Quast C, Knittel K et al (2007) SILVA: a comprehensive online resource for quality checked and aligned ribosomal RNA sequence data compatible with ARB. Nucleic Acids Res 35:7188-7196. https://doi.org/10.1093/nar/gkm864

39. Quast C, Pruesse E, Yilmaz P et al (2013) The SILVA ribosomal RNA gene database project: improved data processing and web-based tools. Nucleic Acids Res 41:590-596. https://doi. org/10.1093/nar/gks1219

40. Mcmurdie PJ, Holmes S (2013) phyloseq: an R package for reproducible interactive analysis and graphics of microbiome census data. PLoS ONE 8:e61217. https://doi.org/10.1371/journ al.pone. 0061217

41. Foster ZSL, Sharpton TJ, Gru NJ (2017) Metacoder: an R package for visualization and manipulation of community taxonomic diversity data. PLoS Comput Biol 13:e1005404. https://doi. org/10.1371/journal.pcbi.1005404
42. Cirimotich CM, Dong Y, Clayton AM et al (2011) Natural microbe-mediated refractoriness to plasmodium infection in Anopheles gambiae. Science 332:855-858. https://doi. org/10.1126/science.1201618

43. Ngo CT, Romano-Bertrand S, Manguin S, Jumas-Bilak E (2016) Diversity of the bacterial microbiota of Anopheles mosquitoes from binh Phuoc Province, Vietnam. Front Microbiol 7:1-11. https://doi.org/10.3389/fmicb.2016.02095

44. Duguma D, Rugman-Jones P, Kaufman MG et al (2013) Bacterial communities associated with Culex mosquito larvae and two emergent aquatic plants of bioremediation importance. PLoS ONE 8:1-11. https://doi.org/10.1371/journal.pone.0072522

45. Kampfer P, Lindh M, Terenius O et al (2006) Thorsellia anophelis gen. nov., sp. nov., a new member of the Gammaproteobacteria. Int J Syst Evol Microbiol 56:335-338. https://doi. org/10.1099/ijs.0.63999-0

46. Briones AM, Shililu J, Githure J et al (2008) Thorsellia anophelis is the dominant bacterium in a Kenyan population of adult Anopheles gambiae mosquitoes. Int Soc Microb Ecol 2:74-82. https://doi.org/10.1038/ismej.2007.95

47. Damiani C, Ricci I, Crotti E et al (2010) Mosquito-bacteria symbiosis: the case of Anopheles gambiae and Asaia. Microb Ecol 60:644-654. https://doi.org/10.1007/s00248-010-9704-8

48. Straif SC, Mbogo CNM, Toure AM et al (1998) Midgut bacteria in Anopheles gambiae and An. funestus (Diptera: culicidae) from Kenya and Mali. J Med Entomol 35:222-226. https://doi. org/10.1093/jmedent/35.3.222

49. Tchioffo MT, Boissière A, Abate L et al (2016) Dynamics of bacterial community composition in the malaria mosquito's epithelia. Front Microbiol 6:1-9. https://doi.org/10.3389/fmicb.2015.01500

50. Diallo M, Sangaré D, Traoré A et al (2015) Etude de l'impact des gites larvaires sur l'infectivite des gamétocytes de plasmodium falciparum chez Anopheles gambiae sl en zone d'endémie palustre de Nanguilabougou-Mali. Mali Méd 30:28-33

51. Raharimalala FN, Boukraa S, Bawin T et al (2016) Molecular detection of six (endo-) symbiotic bacteria in Belgian mosquitoes: first step towards the selection of appropriate paratransgenesis candidates. Parasitol Res 115:1391-1399. https://doi.org/10.1007/ s00436-015-4873-5

52. Osei-Poku J, Mbogo CM, Palmer WJ, Jiggins FM (2012) Deep sequencing reveals extensive variation in the gut microbiota of wild mosquitoes from Kenya. Mol Ecol 21:5138-5150. https:// doi.org/10.1111/j.1365-294X.2012.05759.x

53. Buck M, Nilsson LKJ, Brunius $C$ et al (2016) Bacterial associations reveal spatial population dynamics in Anopheles gambiae mosquitoes. Sci Rep 6:1-9. https://doi.org/10.1038/srep22806

54. Xia X, Zheng D, Zhong H et al (2013) DNA sequencing reveals the midgut microbiota of Diamondback Moth, Plutella xylostella (L.) and a possible relationship with insecticide resistance. PLoS ONE. https://doi.org/10.1371/journal.pone.0068852

55. Dada N, Sheth M, Liebman K et al (2018) Whole metagenome sequencing reveals links between mosquito microbiota and insecticide resistance in malaria vectors. Sci Rep 8:1-13. https://doi. org/10.1038/s41598-018-20367-4

56. Gomgnimbou APK, Savadogo PW, Nianogo AJ, Millogo-rasolodimby J (2009) Usage des intrants chimiques dans un agrosystème tropical: diagnostic du risque de pollution environnementale dans la région cotonnière de l' est du Burkina Faso. Biotechnol Agron Soc Environ 13:499-507

57. Badolo A, Traore A, Jones CM et al (2012) Three years of insecticide resistance monitoring in Anopheles gambiae in Burkina Faso: resistance on the rise? Malar. https://doi. org/10.1186/1475-2875-11-232

58. Toé KH, Jones CM, N'Fale S et al (2014) Increased pyrethroid resistance in malaria vectors and decreased bed net effectiveness, 
Burkina Faso. Emerg Infect Dis. https://doi.org/10.3201/eid20 10.140619

59. Dabiré RK, Namountougou M, Diabaté A et al (2014) Distribution and frequency of KDR mutations within Anopheles gambiae sl populations and first report of the ace: 1 G119S mutation in Anopheles arabiensis from Burkina Faso (West Africa). PLoS ONE 9:e101484

60. Dabiré RK, Namountougou M, Sawadogo SP et al (2012) Population dynamics of Anopheles gambiae sl in Bobo-Dioulasso city: bionomics, infection rate and susceptibility to insecticides. Parasites Vectors 5:127

61. Namountougou M, Simard F, Baldet T et al (2012) Multiple insecticide resistance in Anopheles gambiae s.l. populations from Burkina Faso, West Africa. PLoS ONE 7:e48412. https:// doi.org/10.1371/journal.pone.0048412

62. Capone A, Ricci I, Damiani C et al (2013) Interactions between Asaia, Plasmodium and Anopheles: new insights into mosquito symbiosis and implications in Malaria Symbiotic Control. Parasites Vectors 6:1. https://doi.org/10.1186/1756-3305-6-182

63. Institut National de la Statistique et de la Démographie (INSD), Programme d'Appui au Développement Sanitaire (PADS),
Programme National de Lutte contre le Paludisme (PNL), ICF (2018) Enquête sur les indicateurs du Paludisme (EIPBF) 20172018. Rockville, Maryland, USA : INSD, PADS, PNLP et ICF

64. Baldini F, Segata N, Pompon J et al (2014) Evidence of natural Wolbachia infections in field populations of Anopheles gambiae. Nat Commun 5:3985. https://doi.org/10.1038/ncomms4985

65. Wiwatanaratanabutr I (2013) Geographic distribution of wolbachial infections in mosquitoes from Thailand. J Invertebr Pathol 114:337-340. https://doi.org/10.1016/j.jip.2013.04.011

66. Jeffries CL, Lawrence GG, Golovko G et al (2018) Novel Wolbachia strains in Anopheles malaria vectors from Sub-Saharan Africa. Wellcome Open Res 3:113. https://doi.org/10.12688/wellc omeopenres.14765.1

Publisher's Note Springer Nature remains neutral with regard to jurisdictional claims in published maps and institutional affiliations. 